\title{
O Susto e a Ordem: o Barroco como Ferramenta de Análise da Formação do Brasil
}

\author{
Wallace Faustino da Rocha Rodrigues ${ }^{1}$
}

\begin{abstract}
Resumo
Expondo a relevância do Barroco enquanto possibilidade de interpretação do Brasil, toma-se como pressuposto as dúvidas lançadas pelo mundo moderno à constituição do sujeito ibérico e, igualmente, português. Desse modo, diante dos questionamentos promovidos à sua cosmologia, de tradição tomista, e da derrota deste projeto, tal como formulado por Richard Morse, pretende-se observar como esses elementos se enveredam na colonização do Brasil. A nova terra, contudo, leva às últimas consequências seus questionamentos, restando apenas o Barroco enquanto alternativa para a construção de algum sentido para sua vida e, consequentemente, a construção de um novo povo.
\end{abstract}

Palavras-chaves: Barroco. Brasil. Colonização. Sociedade.

\section{The Shock and the Order: the Baroque as a way of Analyzing THE Formation of Brazil}

\begin{abstract}
The article's aim is to expose the relevance of the Baroque as a possibility for the interpretation of Brazil, taking for granted many doubts cast by the modern world on the establishment of the Iberian (and also Portuguese) subject. Thus, in the face of the questions raised by the Thomist tradition's cosmology, and with the defeat of this project, as formulated by Richard Morse, we intend to observe how these elements are involved in Brazil's colonization. Life in the new land, however, increases those questions, leaving only the Baroque as an alternative to building a meaning to the Iberian subject's life and hence, to the construction of a new people.
\end{abstract}

Keywords: Baroque. Brazil. Colonization. Society.

1 Doutor em Ciências Sociais pela Universidade Federal de Juiz de Fora (UFJF), Brasil. wallacefaustinorocha@hotmail.com 


\section{INTRODUÇÃo}

Hoje, o Barroco, tão controverso em sua essência, como o diz o próprio nome (CHECA; MORÁN, 2001), é reconhecido como a primeira manifestação artística de um povo inteiro, do Brasil, após sua colonização. Mas nem sempre foi assim. O próprio Antônio Cândido, nos anos de 1950, ao fazer um dos primeiros e abrangentes estudos sobre a literatura brasileira, esboçando propósitos genealógicos, deixava de lado o Barroco. Tal ausência na monumental obra de um dos principais intelectuais brasileiros da atualidade é notada (CÂNDIDO, 2006).

Haroldo de Campos foi quem chamou a atenção para a questão do Barroco na constituição da literatura brasileira, evocando a poesia de Gregório de Mattos e Guerra e seu artifício alegórico na construção de uma realidade a proporcionar comparação direta com o "desordenado mundo" questionado pelo Boca do Inferno (CAMPOS, 2004). Antônio Vieira, igualmente, também pode ser tomado como brasileiro2 e os seus sermões, que tratam do Brasil, colorem o imaginário da colônia em construção. Diversos seriam os outros exemplos tratados e que poderiam percorrer, pelo menos, os três primeiros séculos do Brasil. Por conseguinte, o diálogo com o entendimento de Haroldo de Campos que compreende a literatura brasileira - e, por que não, a arte brasileira - como sendo desprovida de infância (do latim, in-fans, "o que não fala"), é inevitável. Trata-se, neste caso, de considerar a literatura, a arte brasileira, tal como seu povo, como nascendo adultos e, portanto, falantes, sem um princípio bem definido (CAMPOS, 2004).

2 O jesuíta Antônio Vieira nasceu em Portugal, mas, entre idas e vindas, fez a sua formação toda no Brasil, inclusive seus votos. Ademais, atuou como missionário, escreveu grande parte de seus sermões - e tomou consciência da importância destes mesmos sermões enquanto textos a serem divulgados, organizando alguns deles que viriam a ser publicados ainda em vida (AZEVEDO, 2008). Raymundo Faoro classifica-o como aquele que constrói a primeira narrativa ficcional de um povo, o povo brasileiro (FAORO, 1997). Morreu, em 1697, em Salvador, Bahia. 
O objetivo deste artigo é justamente o de chamar a atenção para a importância do Barroco na formação da identidade do povo brasileiro. Para tanto, presume-se uma autenticidade em seu processo de formação a levar em conta uma trajetória completamente distinta daquela visualizada na Europa colonizadora. Assim, o Brasil não responderia às chamadas premissas ocidentais modernas a figurarem o racionalismo moderno, e tampouco mostrar-se-ia como uma variante do derrotado projeto neotomista persistente na colonização ibérica da América, tal como formulado por Richard Morse (MORSE, 1989). Desse modo, a sociedade brasileira, ao mesmo tempo, distanciase dos dois modelos de modernidade, implicando ausência de uma referência segura para a constituição de seu sujeito que, de certa forma, configuraria o comprometimento quanto à efetivação de processos de socialização, de estruturação de instituições políticas e, até mesmo, de configuração de uma identidade social a se manifestar, por exemplo, através de sua cultura e sua arte. Diante da ameaça de dissolução da razão humana, o Barroco surge como artifício para a configuração de uma identidade brasileira, forjando as possibilidades de convivência social e moldando sua sociabilização.

O artigo está imerso em um propósito reflexivo que, portanto, abordará brevemente os pontos propostos, tendo o seu autor plena consciência quanto à complexidade do tema analisado. Da mesma maneira, escusa-se do projeto de traçar uma genealogia do povo brasileiro diante do propósito de se criar bases para questionamentos futuros. Por conseguinte, o texto encontra-se estruturado de maneira que, primeiro, faz-se uma apresentação da perspectiva do Barroco admitida nesta hipótese, distanciando-se do formalismo exigido pela História da Arte, vendo-o, em contrapartida, como uma forma de vida a configurar, portanto, um sentido ontológico. Por este caminho, toca-se na ideia de constituição do homem brasileiro, o colono, expondo-o como alguém a buscar um sentido para o seu mundo, 
agora, gigantesco e desconhecido diante de seus olhos. Dessa busca de sentido, na intencionalidade de ordenar o estranho ao seu redor, surgiriam elementos característicos da sociabilidade brasileira, como o patriarcalismo.

Logo, o tom do debate permite o reconhecimento da autenticidade da constituição do brasileiro que não é nem índio, nem português, nem negro escravizado. Não cultiva nenhuma dessas tradições culturais de maneira plena, mas, em contrapartida, mesclaas, assimilando-as como pressuposto de sua constituição, seja no interior da casa-grande, seja nos escuros cantos da senzala. A questão, aqui, não é "como isso ocorre?" mas, mais importante, "por que ocorre?". E, então, este fato é tomado como fundamental, como ponto de partida para o reconhecimento de uma identidade no Brasil.

\section{O susto}

Apenas 13 anos depois do descobrimento do Brasil vinha à luz a obra de Maquiavel, O príncipe. Destarte qualquer propósito de interpretação maquiaveliana, o importante a salientar aqui é a maneira como o autor florentino percebia a sociedade de então, refletindo, claramente, uma concepção de mundo diferenciada. No fundo, em sua obra encontra-se expressa a ruptura de uma percepção hierarquizada do mundo sustentada durante toda a Idade Média (MAQUIAVEL, 2012). Trata-se da quebra de uma noção moral objetiva, de viés puramente aristotélico, em nome da expressão subjetiva e capacidade individual a adquirir contornos mais radicais no contratualismo que ascenderia um século depois, com Hobbes ${ }^{3}$ (HOBBES, 1988).

3 Aqui o leitor deve ficar atento ao fato de que o propósito deste texto não é o de fazer uma exaustiva apresentação de teóricos como Maquiavel, Hobbes, entre muitos outros que inauguraram a fase moderna. Trata-se, contrariamente, de expor a consciência de que tais autores estão inseridos em um cenário motivador, isto é, suas produções, na verdade, são reflexos de sua sensibilidade quanto às transformações do mundo em que se encontram. Maquiavel, atento aos questionamentos quanto a uma noção objetiva de moral a sustentar o preceito de uma ordem perfeita do sistema social medieval; Hobbes, sinalizando para 
Ou seja, a preocupação com a ordem e manutenção do poder, elementos que motivaram Maquiavel a escrever sua obra, é igualmente vivenciado pelos reinos ibéricos no momento de descoberta e conseguinte exploração das Américas. Tais fatos são sintomas dessa transformação da forma de se compreender o mundo - a prescreverem desde revoluções científicas, à Kepler e Galilei, por exemplo, até a negação de alguns dos princípios básicos do cristianismo católico, como a constante intervenção divina no mundo.

A visão hierárquica - forma perfeita da criação divina - a fundamentar as ordens cavalheirescas e a obediência quanto ao poder vertical, oriundo do rei, encontra-se fortemente abalada (CHAUNU, 1966). Cervantes traz isso à tona através do enlouquecido Quixote, cuja loucura é reflexo de sua perda em um passado, representado pelos romances de cavalaria, que, por sua vez, ressaltam os princípios hierárquicos de ordenamento do mundo com uma moral objetiva a reger o comportamento humano (CERVANTES, 2004). O homem não consegue mais espelhar a organização do mundo real, em que vive, no mundo divino - tanto que Quixote é pura ação, pura tentativa de transformação deste mundo pela incapacidade de vê-lo como realmente é. O neotomismo, primeiramente com Francisco de Vitoria e a então fundada Escola de Salamanca, é a manifestação clara da escolástica na tentativa de resolver tais dúvidas ao longo deste século, o XVI, com a aguçada reflexão sobre a diferenciação existente entre lei positiva e lei natural, sendo, resumidamente, a primeira criada pelo homem, segundo a razão conferida por Deus a ele. Assim, o homem espelha o ordenamento de seu mundo ${ }^{4}$, suas leis, a partir da ideia de

a autonomização do sujeito em vista dessa noção objetiva de moral - algo como o sujeito abandonado em seu próprio mundo. Muitos outros autores poderiam ser citados e avaliados nestas linhas, mas, por economia, optou-se por mencionar, sem o seu devido aprofundamento, esses dois como uma maneira de dimensionar a ideia do pano de fundo que está por trás do argumento final em questão.

4 Notem que, enquanto Vitoria investe na ideia de uma figura central, Deus, como o grande organizador do mundo, reforçando as bases de uma Legislação Suprema, fundada no 
perfeição a vigorar na natureza com leis regidas pelo criador (SKINNER, 1996; VITORIA, 1917).

Ainda neste cenário, ademais da solução para o expansionismo espanhol, a colonização da América surge como novo problema para a percepção e interpretação da abalada cosmologia europeia, uma vez que esse homem europeu encontra-se com seres humanos não prescritos na Bíblia, distinguindo-se completamente da linhagem adâmica. A dúvida quanto ao mundo, seu ordenamento, se agiganta. Ao longo de todo o século o homem busca suplantar estas dúvidas e conferir sentido ao seu abalado mundo, tentando desesperadamente o reencontro com Deus que, à medida em que os questionamentos se avolumam, tornam-se ainda mais distantes, principalmente com o propósito do exercício da fé em foro íntimo originado do Protestantismo - aliás, Lutero, de certa forma, também acaba sendo visto como uma radicalização deste processo de subjetivação do mundo e, consequentemente, da vida (SKINNER, 1996).

Daí se tem o surgimento da ideia de homem barroco. Este homem detém a dúvida, questiona o seu mundo, a sua constituição e, fundamentalmente, a presença de Deus e a Sua exigida hierarquia e ordem. $\mathrm{O}$ eminente distanciamento em relação a Deus e a dificuldade de ver a mão do Criador diretamente na criatura compromete toda a maneira de se compreender o mundo, antes tão bem explicado pela razão tomasiana. Sufocado pela angústia advinda da incerteza de um mundo decadente, tenta reconstruir, de baixo para cima, a ordem vivida por ele outrora e que, em especial no caso espanhol, conferiu-lhe a capacidade de unificação do reino de Espanha diante dos infiéis em uma guerra, contra os muçulmanos, de séculos de duração, mas que, no final, deu corpo à maior monarquia católica do mundo moderno.

princípio objetivo de moral, externa ao homem (SKINNER, 1996; VITORIA, 1917), Maquiavel volta-se para as qualidades do governante em sua capacidade de superar esta possível desordem (MAQUIAVEL, 2012; SKINNER, 2010). Ou seja, como dito antes, o contexto é um só, vivido, porém, de maneira diversa pelas diferentes sociedades. 
Diria Wölfflin que o Barroco é uma evolução do Renascimento (WÖLFFLIN, 2010). De fato, o é. Entretanto, não se trata de uma evolução a ser resumida apenas no conceito de forma. Compreender a arte barroca dos Quinhentos, dos Seiscentos e Setecentos é transcender a sua expressão, mergulhando no contexto vivido pela civilização europeia de então, e encontrar nela, nesta arte, as dúvidas humanas a contrastarem quase de imediato com a percepção da confiança humana, da perfeição do homem e de seu corpo e do toque de Deus em sua forma, consoante visto no Classicismo, em que toda a beleza das formas é puro objeto do ato da criação. O homem, bom ou mau, não tem mais qualquer certeza quanto à mão de Deus em sua obra, mas deseja acreditar, precisa acreditar, tendo em vista a maneira como toda a sua tradição, toda a sua compreensão de mundo - todo o sentido de seu cosmos - encontra-se atrelado, condicionado, a esta definição (DE LA FLOR, 2005).

Não por acaso Eugenio D'Ors compreende o Barroco como um dos momentos maiores da unificação cultural europeia. Sua interpretação permite a concepção da ideia de as formas do Barroco ultrapassarem os limites de algo puramente periodológico, sinalizando para a existência de uma categoria de Barroco a se perfilar como uma constante da cultura, deixando de ser algo histórico, com data determinada, adquirindo contornos de universalidade. Ou seja, enquanto variedade estilística, pode o Barroco manifestarse em distintas épocas (D'ORS, 1968). Dialogando com D'Ors, Weisbach diagnostica o Barroco como incerteza diante do cosmos. Fala de uma incerteza a se agigantar de tal maneira que "palpita na origem de todo grande impulso humano" (WEISBACH, 1948, p. 35). Heidegger, contemporâneo de Weisbach, interpreta a metafísica como necessidade de satisfazer um tipo de angústia do homem advinda de sua "superdesenvolvida" subjetividade a conferir o caráter de objeto a tudo, inclusive à humanidade e, então, a si mesmo (HEIDEGGER, 
2012). Ou seja, as dúvidas do homem, seu sofrimento, traduzido, aqui, em angústia, sempre se fizeram presentes ao longo dos séculos. Não poderia ser diferente no período dos descobrimentos.

O sentimento de dúvidas em relação ao mundo encontra-se preservado ao longo de toda a história do homem. Benjamin (2012) leva isso às últimas consequências ao desenhar um caminho traçado pela literatura alemã como dotado de um "buraco ontológico", em que não se torna possível encontrar nem a certeza de uma tradição religiosa como a católica, traduzida no naufrágio da razão teológica, tampouco em um racionalismo interno ao homem como aquele vislumbrado ao longo do Iluminismo. O Trauerspiel alemão, ou drama barroco, é o ponto fundamental a conferir identidade ao racionalismo prussiano e todo o seu edifício racional. Isso porque um dos pontos mais marcantes da argumentação de Benjamin está no fato de o Renascimento alemão, em si, representar uma incessante e até mesmo violenta busca pelo Classicismo. Deste modo, o próprio intento da cultura alemã de se movimentar rumo ao clássico engendra uma configuração verdadeiramente barroca e, por sua vez, de inquietude do homem em busca de um sentido. O grande ponto da reflexão benjaminiana, neste caso, refere-se ao fato de o Barroco passar a ser encarado pelo autor não mais como um momento histórico, formalmente definido pela historiografia da arte, mas, mais precisamente, como qualquer movimento do espírito humano em direção à construção de sentido para si no mundo ao qual pertence. Trata-se, notavelmente, de um esforço humano que, no caso do Renascimento, é visível através da necessidade de se esquadrinhar um sentido para a forma assumida pelo homem naquele momento de sua vida (BENJAMIN, 2012).

A despeito de todo o questionamento gerado pela tese de Benjamin quanto ao racionalismo ocidental e, consequentemente, ao racionalismo alemão na Europa fascista, cabe à solidez da compreensão a-histórica do Barroco, tomando-o como uma característica da 
constituição humana a se manifestar diante da existência de uma "tradição", racional ou não (VILLACAÑAS, 2004). O cenário em que ocorre o descobrimento da América e a conquista e aculturação dos respectivos povos é exatamente esse. Portugal e Espanha, com suas respectivas singularidades, tentam resgatar o sentido de um mundo fundado nos princípios morais e objetivos de uma hierarquia divina escorada na Igreja católica (MORSE, 1989).

Como consequência, o colonizador espanhol e português são homens barrocos a buscarem, invariavelmente, a reconstrução de um cosmos que, à medida em que avançam, se distancia gerando cada vez mais dor e incerteza quanto à sua presença neste mundo. E, por tanto correrem atrás da certeza, se movimentam sempre. Os caminhos escolhidos por cada um, Portugal e Espanha, quanto à colonização, variam, segundo as características de cada país e cada território ocupado. Espanha, com um modelo universal de colonização fundado no princípio dos vice-reinados ${ }^{5}$, conserva a ideia de presença de nobres nas colônias, abrindo precedentes para o desenvolvimento de uma elite crioula que terá papel fundamental nos processos de independência alguns séculos mais tarde. Portugal, por sua vez, esquadrinha sua dominação fundando-se em um pragmatismo coerente com as suas necessidades. Assim, centraliza sua dominação sobre as colônias, tentando, na medida do possível, evitar qualquer possibilidade de autonomização (BOXER, 1977).

Todavia, os desafios impostos ao colonizador não seriam menores. A incerteza quanto à sua presença no mundo, aliás, quanto ao próprio sentido de existência deste mundo, estava agora diante do completamente desconhecido. A natureza, cuja sua tradição dizia ser

5 Durante o período de união das duas coroas, Portugal e Espanha, esta preserva em grande medida o modelo administrativo adotado por sua vizinha enquanto domina todo o território colonial português. Ou seja, conserva a ideia de governos gerais ao longo das colônias portuguesas, não alterando consideravelmente a forma de dominação e expropriação dos territórios conquistados (CONSENTINO, 2009). 
criação de Deus, sendo, portanto, algo completamente harmônico, tal como a constituição do próprio homem, se mostrava tão gigantesco e indomado a ponto de só causar opressão (BARBOZA FILHO, 2000). A harmonia com a natureza buscada pela arquitetura barroca, como forma de ressaltar o uníssono da criação, do sentido comum ao cosmos (ARGAN, 2004), já não se torna possível na América, local de natureza desconhecida, com homens igualmente desconhecidos, mas portadores dos segredos naturais que se recusam em ser revelados aos europeus.

Condenado a viver em um mundo de incertezas, o homem barroco, o colonizador europeu, tem como alternativa confiar na reconstrução do sentido do mundo de baixo para cima, tentando a maior aproximação possível com a razão criadora. Uma vez na América, o abandono neste mundo, de natureza extremamente arrogante, por indomável que é, o sentimento de abandono é elevado à última potência. Assim, as ganas pelo ouro e a prata falam mais alto e encontram aquela brecha deixada pela concepção objetiva da moral, fundada em Aristóteles e ampliada em Santo Tomás de Aquino - os principais credores do catolicismo. O desespero, oportunista, ocupa o lugar da razão barroca. O domínio, o necessário extermínio ante qualquer possibilidade de contestação de seu mundo, se faz eminente. Tudo, agora, adorna o sonho de reconstruir o mundo do zero. O criador, mais do que nunca, anseia por se mostrar presente no entendimento deste homem barroco colonizador. E, neste ponto, o Barroco o tira do estatismo, pois a sua singularidade está justamente na capacidade de reprodução pela cultura dos procederes da natureza - diferentemente do Classicismo, cuja tônica é a reprodução pela cultura dos procederes da própria cultura6 (D'ORS, 1968).

6 Este ponto de distinção, de particularismo do Classicismo, torna-se ainda mais visível quando se tem em mente de que o homem é retratado no Renascimento como pura manifestação da beleza, de modo a promover uma identificação do belo com a ideia da criação. Grosseiramente falando, é a cultura do belo reproduzida por meio da cultura que se 
No Brasil o caminho da colonização adquire suas nuances. A natureza, igualmente, mostra-se arrogante. Todavia, as civilizações encontradas não tinham muito a oferecer ao ansioso português que cruzou o oceano - tal como esta mesma natureza que, num primeiro momento, estava desprovida de metais preciosos. Assim, praticamente nada poderia ser extraído dela para a glória do reino português, também ansioso para reconstruir a ideia de hierarquia divina no imaginário de seu povo. Ao mesmo tempo, nada ali configura uma ameaça física imediata e consequente contestação dos princípios tradicionais ibéricos a ungirem o reino lusitano. Logo, o Brasil não precisa ser conquistado. O Brasil não tem nada para ser conquistado.

Ademais, diversas outras questões interferem de maneira a impedir que Portugal empreenda uma efetiva política colonizadora em seus domínios americanos nas primeiras décadas pós descobrimentos - entre elas, a importância maior que gerava o comércio com a Índia, atendendo bem às suas necessidades iniciais como reino (ALENCASTRO, 2000). Desse modo, os primeiros colonizadores desembarcavam nas praias da Terra de Santa Cruz sem qualquer tipo de projeto. Aliás, não por acaso, a colônia foi vista como algo secundário, como terra de degredo, estando completamente desprovida da presença de uma nobreza, como ao contrário ocorreu na América hispânica que detinha uma tradição, de fundo neotomista contestável ou não, na condução dos rumos de colonização.

Os primeiros colonos portugueses na Terra de Santa Cruz detinham a mesma incerteza presente no homem barroco. Deste modo, encontravam-se completamente abandonados à sua sorte, oprimidos, ademais, por uma natureza desconhecida, indomável, opressora a ponto de ameaçar devorá-lo com sua imensa arrogância (BARBOZA FILHO, 2000). Diante de tudo isso, resta apenas fechar-se em seu próprio mundo, cada vez mais caracterizado pelo aspecto pragmático

tem sobre a criação (ARGAN, 1996a, 1996b). 
do "ladrilhador" de Sérgio Buarque de Holanda (HOLANDA, 1996). Não cabe formulações ideológicas. Apenas, sobrevive. E é justamente essa sua constituição barroca, de incertezas que resultam na necessidade do movimento - um movimento de reconstrução, de busca de algo que não sabe o que é - a conferir dinâmica ao seu caráter, embora sem constituir uma direção precisa aos seus movimentos. Inconscientemente, cimenta bases para uma cultura, a sua cultura, a partir dos procederes da desconhecida natureza a devorá-lo com o imprevisível.

Este homem, não mais português, depois de gerações no Brasil, tem de lidar com tudo que lhe é oferecido da maneira como pode, como consegue. Assim é que não cria barreiras à mestiçagem - ainda que isso não configure uma percepção quanto à humanidade; assim é que explora o pau-brasil, como algo quase sem-querer; assim é que leva a cana-de-açúcar para o Brasil; assim é que escraviza, primeiro o índio, depois, o negro, pois é a solução que lhe aparece; assim é que, novamente, se reproduz com seu cativo e leva-o para o interior de sua casa, a casa-grande; assim é que domina patriarcalmente, como forma de controle de seu mundo - aquele mesmo controle almejado desde sempre pelo homem barroco e que não se fez presente no princípio devido à imposição da natureza. Neste último caso, não se trata de um tipo de dominação puramente racional, como caracterizado séculos depois por Max Weber (WEBER, 1999). Há racionalismo, mas o racionalismo prático exigido pelo Barroco.

O colono, enquanto agente, constrói, portanto, a sua realidade de maneira imediata, quase que como um reflexo do mundo, de sua forma de estar no mundo. Determina, a partir de então, suas relações sociais e seu modo de ser, juntamente com a forma como assimila os aspectos mais característicos desta realidade. E tudo é feito com esta imensa paleta de cores, cores fortes, pungentes, e suficientemente destacadas a ponto de entonar um claro-escuro caracteristicamente 
barroco. É no claro que se encontra o seu aspecto mais pragmático, a sua necessidade de se movimentar. Esta dinâmica se faz diante do escuro proveniente da incerteza do caminho tomado pelo seu movimento. $\mathrm{E}$ é com as cores deste claro-escuro - que necessariamente, devem ser bastante fortes para tornar cada vez mais visível o contraste entre os extremos - que o homem colonizador, barroco, pinta a sua realidade e configura o seu modo de ser.

\section{A ORDEM}

Diante de tudo o que foi apresentado acima, a partir de uma sugestão de se tomar o Barroco como ferramenta de análise da formação do Brasil, levando em conta o princípio da existência de um homem barroco fruto das incertezas de seu tempo, pode-se dizer, seguramente, que a História do Brasil é recente. Aos bramidos de desordem, provenientes do comportamento excessivamente pragmático, dá-se o mínimo esforço da monarquia lusitana, na tentativa de preservar o seu império ultramarino, de impor a ordem. Desse modo, Raymundo Faoro autoriza-se a dizer que no Brasil se tem "a criação da realidade pela lei" (FAORO, 1997, p. 120). Em sua preocupação de fazer uma genealogia das instituições políticas brasileiras, de sua singular característica de apropriação privada e configuração sumamente burocratizada, apresenta a coroa Portuguesa como entidade de colossal força política a ponto de garantir uma centralização das mesmas proporções das estruturas políticas brasileiras. O intuito, no entendimento do autor de Os donos do poder, está em identificar a fortíssima presença da metrópole na configuração da colônia. Todavia, o predicado fundamental da tese de Faoro está no eminente caráter secundário assumido pela colônia, traço marcante de seu passado a condená-la a uma eterna heteronomia política. 
O interessante disso tudo está no fato de que à dominação exercida pela coroa Portuguesa está a submissão do povo, relegado ao status de coadjuvante do coadjuvante, pois, em um primeiro plano, sempre, está a metrópole no imenso império ultramarino. Assim, o Brasil é conquistado, ocupado e explorado de maneira que nada seja feito para ele mesmo, mas, fundamentalmente, atendendo aos preceitos de um império, o português, que a maioria dos brasileiros nunca viu. Sérgio Buarque de Holanda escreveu antes, mas, de certa forma, sua fala complementa a de Faoro ao dizer que o brasileiro é "um degredado em sua própria terra" (HOLANDA, 1996, p. 79).

A apropriação da tese de Faoro serve para contextualizar o caráter do Brasil colonial como sendo o de uma terra não existente por si mesma. Desde o princípio, não há a preocupação em se implantar uma cultura, uma tradição, nos dizeres de Rubem Barboza Filho, a configurar identidade para o povo progressivamente crescente (BARBOZA FILHO, 2000). São as consequências da insegurança do presente homem barroco, mencionado anteriormente, entoando um descompasso com o "propósito colonizador" lusitano, centralizado talvez em virtude do temor de perder sua própria colônia. Portugal, especificamente na figura do governador-geral, tinha como preocupação somente a exploração do território brasileiro. Obviamente, o processo é muito mais complexo que isso, pois leva em conta a formação de determinados grupos sociais, como traficantes de escravos, senhores de engenho, entre outros, que se contrabalançariam enquanto forças sociais na organização de algumas das estruturas políticas e econômicas (FERLINI, 2003).

Abrindo parênteses nesta reflexão, é interessante pensar como a implantação de uma administração centralizada denuncia a fragilidade social brasileira. Como visto antes, não há planejamento social, uma vez que o colono é puro susto. Não há a criação de uma complexa rede social diretamente ligada à administração local da 
colônia por meio da admissão, por exemplo, da presença de uma nobreza consistente na investida colonizadora. Distintamente do que se vê nos seus vizinhos ibero-americanos, a nobreza portuguesa sucumbe ao barroquismo palaciano, estando todos em torno do rei e, portanto, distantes dos domínios ultramarinos. Sabe-se do impacto gerado pela presença de uma corte, como a portuguesa, devido aos acontecimentos e aos rumos tomados pelo Brasil pós 1808. O que há, claramente, é a instalação de uma administração quase 50 anos depois da descoberta da Terra de Santa Cruz.

Diante do nada, o tom da incapacidade política e administrativa colore a paisagem brasileira. Era como se o argumento da futilidade de Hirschmann, o mais perverso da intransigente retórica moderna (HIRSCHMANN, 1992), se materializasse e, ao tornar-se carne, verbalizasse o imperativo da interferência, da ajuda. Nisso, tudo é apagado. Tudo prenuncia a necessidade do recomeço. E cada recomeço traz consigo uma ideia como um movimento vertical, de cima para baixo, colonizando depois da conquista deste povo sem passado. Pronto, o brasileiro passa a ter, então, identidade. Uma identidade que, pelo menos desde a sua independência busca desesperadamente o anseio pela inclusão de seu povo na sonhada modernidade, com todo o racionalismo e as ideias das luzes.

À verticalidade das ideologias colonizadoras - reflexos da insegurança do mundo a promover a tentativa constante do domínio, do controle - tem-se a horizontalidade do brasileiro condenado ao rés do chão. Esta vivência ao rés do chão, por si só, é um traço fundamentalmente barroco, de forma a exigir deste homem a sua vivência material, a lida diária com o seu meio sem praticamente nenhuma referência a não ser a sua própria capacidade de racionalização das ações (DELEUZE, 1988). A sua vida, portanto, confunde-se com o imediato, com a necessidade de se fazer com que cada coisa possa ser utilizada para a sua sobrevivência. Logo, se houver 
uma pesquisa quanto à sua identidade, ela deve se dar essencialmente nesta necessidade - depois, capacidade - de o colono conseguir se apropriar de um mundo que o nega constantemente, seja pela incerteza da presença de Deus e a ordem hierárquica do cosmos anteriormente prevista por seu criador, seja pela arrogância da natureza, inimiga quando se tenta domá-la.

Talvez por isso a História do Brasil, ainda que revisitada constantemente, se faça cada vez mais recente e dotada de incertezas quanto à determinação de suas características, quanto à tentativa de classificar a identidade de seu povo, de seu jovem povo que, como disse o já evocado Haroldo de Campos, tem uma cultura nascida adulta, tal como o Macunaíma, de Mário de Andrade (ANDRADE, 2000). E, como adulta, nunca foi afásica (CAMPOS, 2004). Mas, como se sabe, esse processo de formação do Brasil tem um lado fundamentalmente cruel. Trata-se de uma crueldade a obrigar este colono - agora, sim, podendo ser chamado de brasileiro - a viver ao rés do chão, devendo antes de mais nada, corrigir as plantas de seus pés e fincar-se em seu meio. Deve-se, logo, traduzir-se em seu próprio meio, sendo-lhe impossível, e incapaz, de projetar-se para o alto, despregar-se de seu mundo, de seu chão. Essa é, talvez, a única característica comum ao senhor de engenho, ao escravo, ao índio, ao português colonizador e muitos outros atores do gigantesco e, outrora, edênico mundo, novamente, nos dizeres de Buarque de Holanda (HOLANDA, 1977).

O ditame é a exploração e a satisfação da economia colonial. O Brasil é somente um elemento a mais no imenso comércio atlântico criado por Portugal. Tudo é secundário em seu afã de afirmação perante a um mundo que se torna estranho, cada vez mais estranho, até mesmo para ele. $\mathrm{O}$ que se passa no Brasil, colônia como qualquer outra, é mera consequência. O que se monta no Brasil, em termos de aparatos político-administrativos, é puro meio para uma finalidade clara, bem definida e de comum conhecimento de todos. A maior 
colônia lusitana, então, é submetida, impondo-lhe uma condição de existência que, justamente, implica não existir por si mesma. Estão criadas, portanto, as bases para a sua ocupação da maneira como o foi.

E o Brasil se faz no susto. O mesmo susto tomado pelo colono, no quadro de Debret, ao ver a Proclamação da Independência. A proliferação da cana no litoral também acaba sendo produto desse susto - talvez, um dos primeiros. Todavia, o conhecido investimento exigido pelo engenho de açúcar, com uma dinâmica produtiva difícil de imaginar, acompanhado do alto custo de sua implantação, ganha corpo na colônia. Com o açúcar, garante-se, em alguma medida, o domínio, secundariamente, a colonização, e, por sua vez, mobiliza lucros para a metrópole - obviamente, lucros inimagináveis inicialmente. Todavia, trata-se de uma mobilização de capital a prefigurar a restrição quanto à sua participação. Não por acaso, a coroa portuguesa acaba sendo uma das principais incentivadoras e financistas no processo de implantação das moendas no litoral brasileiro ao longo dos dois primeiros séculos de colonização. De toda forma, é evidente a restrição quanto às possibilidades de participação na atividade, já conhecida entre os portugueses por sua experiência nas ilhas do Atlântico (FERLINI, 2003).

Sem qualquer sombra de dúvida, a figura do senhor de engenho, no Brasil, tende a refletir o significado mais puro da economia colonial. Ao mesmo tempo em que se mostra detentor de grande capital, materializado no volumoso investimento que é o engenho de açúcar, está assaz distante daquilo que pode ser chamado de economia moderna, principalmente se se tomar em conta a sua persistente insistência no escravismo. De todo modo, seu poder político, econômico e social, então, não pode ser desconsiderado. Os matizes de tal poder apresentam algumas das chaves a permitirem uma melhor compreensão do que se passa na colônia portuguesa. Definitivamente, Gilberto Freyre mostra-se como o primeiro a atentar 
para isso de forma tão sóbria, observando as consequências do exercício de tal poder nas diferentes esferas dignas da análise sociológica. Em seu estudo, o patriarcalismo passa de simples termo a conceito operativo fundamental para a interpretação da sociedade colonial. É através do patriarcalismo que se vislumbra o eixo vertical do poder do senhor de engenho, ainda que se deva fazer uma relativização das argumentações freyreanas em torno da questão da admissão do negro no interior da casa-grande, vendo-o como um aspecto fundamental, com termos positivos, para a mistura das raças (FREYRE, 2006).

De fato, a configuração assumida pelo controle real da colônia, pela tentativa de monopólio de seu poder administrativo, amputa do senhor de engenho a possibilidade de ampliação de seu poder político. Há, a partir desta investida, uma espécie de condenação do engenho a um canto, atribuindo a ele um determinado espaço que, de maneira alguma, deve ser ultrapassado. Como consequência, o engenho e toda a mecânica social por ele exigida, é condenado a uma espécie de ilha, num isolamento materializado geograficamente pelo latifúndio. Tais ilhas, providas sempre de casas-grandes, senzalas e moendas senhores, escravos e monocultura de cana - detêm regras próprias a figurarem o poder patriarcal, cujo lado mais cruel está na liberdade de dominar a liberdade do outro, privando-o dela.

Por um lado, esse poder patriarcal, nos termos de Freyre, indica a solvência de qualquer possibilidade de emancipação de individualidades ao configurar a submissão de todos à mão do senhor. Durante o período colonial e grande parte do Brasil Império, o senhor de engenho, no campo, torna-se alguém intocável, provido de poderes sobre os seus. Morre, mas a ideia de um status, de senhor de engenho, não. Outro, de sua linhagem, ocupa o seu lugar, e, a despeito da variação de personalidades, opera segundo a mesma lógica reproduzindo tudo o que lhe antecedia (FARIA, 1998). Não se pode falar em disputa de classes neste caso. Há, pelo contrário, um 
estamento a se perpetuar, configurando uma dominação permanente sobre aqueles que the rodeiam.

A singular característica dessa dominação, figurada pela solidez do estamento senhorial, sublinha a dependência e consequente despersonalização dos estratos sociais encontrados abaixo. Torna-se impossível falar em uma autonomização desses seres e, principalmente, dos escravos. A individualização e o próprio reconhecimento como indivíduo é algo praticamente impossível, tendo em vista a submissão de tudo e todos à vontade e, mais grave ainda, à ideia da vontade do senhor de engenho. A dinâmica social prefigura o condicionamento da vida à lógica exigida pelo senhor. A obediência em todas as instâncias sublinha a regra geral: primeiro obedecer e, se sobrar espaço, somente depois questionar "quem eu sou e o que faço" (COSTA, 1998).

De alguma forma, portanto, o embrionário anseio por ordem vislumbrado pelos primeiros colonos quando chegaram à imensa e desconhecida Terra de Santa Cruz encontra uma forma através do patriarcalismo e da figura do senhor de engenho. $\mathrm{O}$ anseio pela dominação motivado pelo temor da desordem acaba funcionando como uma espécie de barreira à objetivada moral neotomista, descrita tão preciosamente por Morse (MORSE, 1989). Sua constituição barroca funciona como uma espécie de força centrípeta, tragando tudo para o seu interior no âmbito de conferir um sentido para todas as coisas, mais precisamente, o único sentido que pode conhecer, aquele ligado à sua constituição enquanto agente ímpar, desejoso do domínio, da hierarquia, da verticalização do grupo social. Criam-se limites em seu alcance visual, impedindo-o de ver com clareza a separação entre o público e o privado e, naturalmente, de delimitar o que é humano e o que não é, facilitando com que tudo seja abrangido pela lavoura canavieira na forma de mão-de-obra escrava.

Deste modo, não é exagerado voltar-se para o senhor de engenho como forma de fazer uma projeção da ordem social e os 
princípios e regras para a socialização na colônia portuguesa nas Américas. Freyre percebeu isso, manipulou o patriarcalismo como conceito fundamental da vertical sociedade colonial, e vislumbrou a casa-grande como um microcosmo do Brasil açucareiro. Destarte todo o possível diálogo existente entre as esferas opostas, senhor e escravo, demonstrado por meio das imagens de convivência no interior da residência senhorial, predomina o desejo da verticalização de toda essa estrutura e, consequentemente, das relações de poder e dominação por meio do escravismo como um axioma e do lugar destinado à senzala (FREYRE, 2006).

"Pachorra": esta é a palavra que Fernando Henrique Cardoso utiliza para descrever a forma como Gilberto Freyre apresenta o Brasil no prefácio de uma das edições de Casa-grande e senzala (CARDOSO, 2006). E, de fato, há por parte do autor uma aparente busca pela conciliação das raças a partir do momento em que toma a mestiçagem como um processo comum, natural e, de certa forma, tendo em vista a experiência transcultural portuguesa, tão assinalado por Sérgio Buarque de Holanda (HOLANDA, 1996). O mito de Malinche, nos termos descritos por Bolívar Echeverría (ECHEVERRÍA, 2011), no caso brasileiro, abandona o aspecto da dominação, da conquista e seu caráter estratégico, a pressupor uma intencionalidade, ficando somente com o elemento do novo, da construção de um povo distinto, inovado por dentro e por fora, com o "açúcar na ponta da língua": o mulato (FREYRE, 2006).

Sem embargo, é imprudente, senão irresponsável, dizer que Freyre dulcifica de maneira completa a visão sobre o Brasil. O que ele faz, definitivamente, é exigir uma visão original sobre este país, reconhecendo a autenticidade no processo de formação de seu povo. Isso é mais verdade ainda quando se toma o patriarcalismo como ponto fundamental de suas argumentações. Esse patriarcalismo, lido também como poder do senhor de engenho, é o que organiza o meio ao seu 
redor, determinando os aspectos mais claros de sua constituição social a ponto de caracterizar não mais somente a organização do campo, da casa-grande e senzala (e engenho), mas, nas mesmas proporções, as primeiras cidades, com os seus sobrados e mocambos (FREYRE, 1977). Não cabe mais apenas o olhar julgador sobre o Brasil, vendo-o como distúrbio de uma sociedade autenticamente moderna. Ao mesmo tempo, isso não significa abandonar o pressuposto hierárquico, de domínio, portanto, vertical, dessa organização social. Por conseguinte, os que vêm depois de Gilberto Freyre na tentativa de interpretar o Brasil, valendo-se, inclusive, de sua obra, tornam-se autorizados a falar de força, de violência, de sujeição - principalmente tomando-se em conta a perspectiva do escravo negro - sem, contudo, corromper a ideia inicial do célebre autor. Repita-se: o princípio de Freyre está no reconhecimento da originalidade da constituição do povo brasileiro a pressupor uma forma única, singular, de convivência de grupos sociais tão opostos, como o negro e o branco na figura de escravos e senhores, respectivamente. $\mathrm{O}$ autor de Casa-grande e senzala, neste caso, apenas não viu a barroca constituição do colonizador que, de certa forma, é mobilizado pelo susto da incerteza quanto ao seu mundo.

E, enfim, por trás de todo o questionamento, toda a dúvida proveniente da incerteza quanto ao cosmos, à criação divina que cruza o Oceano, à hostilidade da natureza e o consequente desafio em utilizá-la como fonte para a reprodução de uma cultura, o brasileiro surge. Organiza o mundo à sua maneira, sem referenciais, mas consciente da ofensa do caos, que pode ser elevado à última potência em um ambiente a insistir em ser superior. Por isso, busca a calma e a sobriedade pelos caminhos mais tortuosos, expressando-as de forma considerável nas fachadas das igrejas barrocas, demonstradas que, na descrição de Lourival Gomes Machado, contrastam, em sua tranquilidade e paz, com o interior repleto de detalhes a espelharem a intranquilidade da alma humana e a expor o homem diante dos 
seus maiores temores (MACHADO, 2003). E este homem brasileiro, condenado ao rés do chão, vive em um pragmatismo a movimentálo por instantes, de maneira que atribua importância aos fatos mais cotidianos, aparentemente mais simples, mas que, em seu olhar, são dotados da maior importância, tal como o homem que carrega a cruz para agradecer ao santo tão próximo a cura da convalescência de seu amigo burro. E, com a cruz nas costas, sentindo a dor de Cristo, deparase diante da calma e tranquilidade da sóbria fachada barroca. Mas, a entrada lhe é negada pela dogmática igreja a alegar a futilidade do motivo (GOMES, 2008). O homem, então, tem o acesso ao seu interior veementemente negado. E essa negação consiste na representação da negação do conhecimento de si mesmo, devido ao reflexo de um sobre o outro. E nesse fechar de portas da igreja, fecham-se igualmente as portas à compreensão do barroco homem brasileiro.

\section{Considerações Finais}

Nestas últimas palavras objetiva-se a distância de qualquer tipo de conclusão quanto à constituição do Brasil e a maneira como deve ser admitida a sociedade brasileira. O propósito, visto como mais saudável para as próprias Ciências Sociais, no campo do Pensamento Social e Político Brasileiro, tal como a História do Brasil, é lançar novas perguntas, como, por exemplo, por que não valer-se do Barroco como possibilidade interpretativa da constituição do Brasil?

De todas as formas, finaliza-se este texto da mesma maneira como foi iniciado. Apela-se para a ideia do entendimento da constituição da sociedade brasileira como algo feito de baixo para cima e, mais complexo ainda, como uma espécie de movimento de resposta às ameaças de seu mundo. $\mathrm{O}$ colono, o assustado colono, responde ao estímulo do mundo que se agiganta cada vez mais diante de seus olhos, saindo-lhe do controle. O seu primeiro movimento, portanto, é 
o de tentar controla-lo. Os referenciais sociais deste colono encontramse justamente em dúvida quanto à sua cosmologia do outro lado do mundo. Os referenciais políticos, por sua vez, vêm na forma de massacre, de um arbitrário controle administrativo promovido pela metrópole, interessada, apenas, em manter o território descoberto e produzir para os seus próprios lucros, sem oferecer algo em troca. Nada mais importa, impedindo-a de elaborar um consistente projeto de colonização e, consequentemente, de ver a Terra de Santa Cruz como uma extensão do reino lusitano.

Ao colono, o tão próximo ancestral do brasileiro moderno, o único brasileiro que existe e existiu, resta o Barroco como o movimento do espírito a lhe preencher o eco deixado pelo mundo sem sentido. Nesta imensa bricolagem sem estrutura, recria o mundo segundo a sua necessidade, valendo-se apenas de seus instintos - ou dobras do espírito, na versão deleuziana do Barroco. O sentido, junto com a ordem almejada, são criações que se vão superpondo, como camadas, construindo um imenso e sólido edifício cultural, cujas mônadas, em seu sentido mais lebniziano, se movimentam irrefreavelmente todas ao mesmo tempo (DELEUZE, 1988). Para nada, portanto, há o antes ou o depois. Tudo se dá ao mesmo tempo, sem ordem pré-determinada. Tudo se constrói unicamente pela urgência.

Enfim, olhar para o Brasil admitindo esta perspectiva, estes complexos processos de constituição de sua sociabilidade, ademais de ser um olhar inovador, pode sinalizar para uma compreensão de sua sociedade, de sua cultura, dos princípios a regerem as relações sociais, ainda não vista no interior do Pensamento Social e Político Brasileiro, ainda preso à necessária trajetória iluminista de compreensão do homem moderno realizando, sem perceber, a mesma negação ao conhecimento deste homem, outrora feito pelo escolasticismo. Não custa tentar. 


\section{REFERÊNCIAS}

ALENCASTRO, Luiz Felipe de. O trato dos viventes: a formação do Brasil no Atlântico Sul. São Paulo: Companhia das Letras, 2000.

ANDRADE, Mário de. Macunaíma: o herói sem nenhum caráter. Belo Horizonte: Garnier, 2000.

ARGAN, Giulio Carlo. Renacimiento y Barroco I: de Giotto a Leonardo da Vinci. Madrid: Alral Ediciones, 1996a.

ARGAN, Giulio Carlo. Renacimiento y Barroco II: de Miguel Ángel a Tiépolo. Madrid: Alral Ediciones, 1996b.

ARGAN, Giulio. Imagem e persuasão: ensaios sobre o Barroco. São Paulo: Companhia das Letras, 2004.

AZEVEDO, João Lúcio. História do Padre Antonio Vieira. São Paulo: Alameda, 2008.

BARBOZA FILHO, Rubem. Tradição e artifício: iberismo e barroco na formação americana. Belo Horizonte: Ed. UFMG; Rio de Janeiro: IUPERJ, 2000.

BENJAMIN, Walter. El origen del Trauerspiel alemán. Madrid: Abada Editores, 2012. BOXER, Charles. O império colonial português. Lisboa: Edições Lisboa, 1977.

CAMPOS, Haroldo. Barroco literário brasileño. In: HARO, Pedro Aullón. Barroco. Madrid: Editorial Verbum, 2004. p. 1109-1116. (Serie Teoría Crítica).

CÂNDIDO, Antônio. Formação da literatura brasileira: momentos decisivos 17501880. Rio de Janeiro: Ouro sobre Azul, 2006.

CARDOSO, Fernando Henrique. Prefácio. In: FREYRE, Gilberto. Casa-Grande e senzala: formação da família brasileira sob o regime da economia patriarcal. São Paulo: Global, 2006.

CERVANTES, Miguel. El ingenioso Hidalgo Don Quijote de la Mancha. Barcelona: Planeta, 2004.

CHAUNU, Pierre. La civilisation de l'Europe classique. Paris: Arthau, 1966.

CHECA, Fernando; MORÁN, José Miguel. El Barroco. Madrid: Istmo, 2001.

COSENTINO, Francisco Carlos. Governadores gerais do Estado do Brasil (séculos XVIXVII): ofício, regimentos, governação e trajetórias. São Paulo: Annablume; Belo Horizonte: Fapemig, 2009. 
COSTA, Emília Viotti. Da senzala à colônia. São Paulo: Fundação Editora da UNESP, 1998.

D'ORS, Eugenio. Du Baroque. Paris: Gallimard, 1968.

DE LA FLOR, Fernando. Pasiones frías: secreto y disimulación en el Barroco hispano. Madrid: Marcial Pons Historia, 2005.

DELEUZE, Gilles. El pliegue: Leibniz y el Barroco. Barcelona: Ediciones Paidós Ibérica, 1988.

ECHEVERRÍA, Bolívar. La modernidade de lo Barroco. México D. F.: Ediciones Era, 2011.

FAORO, Raymundo. Os donos do poder: formação do patronato político brasileiro. São Paulo: Editora Globo, 1997.

FARIA, Sheila de Castro. A colônia em movimento: fortuna e família no cotidiano colonial. Rio de Janeiro: Editora nova Fronteira, 1998.

FERLINI, Vera. Terra, trabalho e poder: o mundo dos engenhos no Nordeste colonial. Bauru: EDUSC, 2003.

FREYRE, Gilberto. Casa-grande E senzala: formação da família brasileira sob o regime da economia patriarcal. São Paulo: Global, 2006.

FREYRE, Gilberto. Sobrados e mocambos: decadência do patriarcado rural e desenvolvimento do urbano. Rio de Janeiro: José Olympio, 1977.

GOMES, Dias. O pagador de promessas. Rio de Janeiro: Bertran, 2008.

HEIDEGGER, Martin. Ser e tempo. Petrópolis: Vozes, 2012.

HIRSCHMAN, Albert. A retórica da intransigência: perversidade, futilidade e ameaça. São Paulo: Companhia das Letras, 1992.

HOBBES, Thomas. O leviatã: ou matéria, forma e poder de um Estado eclesiástico e civil. São Paulo: Nova Cultural, 1988.

HOLANDA, Sérgio Buarque. Raízes do Brasil. São Paulo: Companhia das Letras, 1996.

HOLANDA, Sérgio Buarque. Visão do paraíso: os motivos edênicos do descobrimento e colonização do Brasil. São Paulo: Companhia das Letras, 1977.

MACHADO, Lourival Gomes. Barroco mineiro. São Paulo: Perspectiva, 2003.

MAQUIAVEL, Nicolau. O príncipe. Porto Alegre: L\&PM, 2012. 
MORSE, Richard. O espelho de próspero: cultura e idéias nas Américas. São Paulo: Companhia das Letras, 1989.

SKINNER, Quentin. As fundações do pensamento político moderno. São Paulo: Companhia das Letras, 1996.

SKINNER, Quentin. Maquiavel. Porto Alegre: L\&PM, 2010.

VILLACAÑAS, José Luis. Gracián en el paisaje filosófico alemán: una lectura desde Walter Benjamin, Arthur Schopenhauer y Hans Blumenberg. In: HARO, Pedro Aullón de. Barroco. Madrid: Editorial Verbum, 2004. p. 697-718. (Serie Teoría Crítica).

VITORIA, Francisco de. Relecciones teológicas. Madrid: Librería Religiosa Hernández, 1917.

WEBER, Max. Economia e sociedade. Brasília: Editora da UnB, 1999.

WEISBACH, Werner. El Barroco: arte de la contrarreforma. Madrid: Espasa-Calpe, 1948.

WÖLFFLIN, Heinrich. Renascença e Barroco: estudo sobre a essência do estilo Barroco e a sua origem na Itália. São Paulo: Perspectiva, 2010. 